\title{
Ending preventable maternal and newborn mortality and stillbirths
}

\author{
DorQ1ou and colleagues discuss the strategic priorities needed to prevent maternal and \\ nev
}

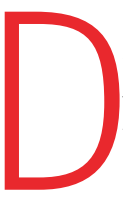
espite remarkable achievements to improve maternal and child survival, 800 women and 7700 newborns still die each day from complications during pregnancy, childbirth, and in the postnatal period; an additional 7300 women experience a stillbirth. ${ }^{1-3}$ Some countries have been able to improve health outcomes for women and children, even with relatively low health expenditures. ${ }^{4}$ The key to their success can be found in context specific, evidence informed strategies to improve and integrate care, supported by strong guiding principles and good governance. ${ }^{5}$

This paper builds upon two strategic plans-Every Newborn: An Action Plan to End Preventable Deaths (ENAP) and the Strategies toward Ending Preventable Maternal Mortality (EPMM) ${ }^{67}$-that aim to catalyse global action to eliminate wide disparities in the risk of death and end preventable maternal and newborn mortality and stillbirths within a generation (box 1). We discuss the strategic priorities and essential interventions needed to prevent maternal and newborn deaths and stillbirths and promote maternal and newborn health and wellbeing.

\section{Methods}

A complete review and mapping of the elements of ENAP and EPMM was undertaken.

\section{KEY MESSAGES}

Unacceptable levels of maternal and newborn mortality and stillbirths impede the realisation of healthy and sustainable societies

Achieving country and global targets for ENAP and EPMM will contribute to the goals of the Global Strategy for Women's Children's and Adolescents' Health

We present five strategic objectives that should be prioritised to end preventable maternal and newborn deaths and stillbirths, synthesised from the strategic objectives described by ENAP and EPMM The objectives focus on strengthening care around the time of birth; strengthening health systems; reaching every women and newborn; harnessing the power of parents, families, and communities; and improving data for decision making and accountability
Key themes and strategic objectives that were found to be largely similar are discussed in this paper. Where the emphasis or recommended strategic approach varied based on the target population, and the distinctions were deemed important, specific recommendations were retained.

Both strategic plans are based on scientific and empirical evidence, and underwent wide expert consultation with inputs from national, regional, and global meetings, and an official online consultation. ${ }^{789}$ The mortality targets were endorsed by countries, including at the 67th World Health Assembly in $2014 .^{10}$

\section{Limited progress}

As the era of the millennium development goals comes to a close, more needs to be done for women's and children's health. Although maternal deaths declined to 289000 in $2013,{ }^{1}$ the $45 \%$ reduction in maternal mortality since 1990 falls far short of the target of $75 \%$ in millennium development goal 5. The majority of maternal deaths are still due to direct obstetric causes-that is, haemorrhage $(27 \%)$, hypertensive disorders (14\%), sepsis (11\%), and complications of abortion (8\%). ${ }^{11}$ However, a rising number of deaths are related to chronic health conditions in pregnancy, such as diabetes, HIV, malaria, cardiovascular conditions, and obesity (fig 1 ).

Newborn deaths have declined by $40 \%$ since 1990; about 2.8 million newborns died in 2013. The fall in newborn mortality has been slower than that in child mortality, and newborn deaths now account for $44 \%$ of all deaths in children under 5 globally. ${ }^{2}$ The three main causes of newborn deaths are preterm birth complications (35\%), intrapartum conditions (24\%), and infections $(20 \%){ }^{12}$ Almost $80 \%$ of newborn deaths occur among babies who weigh less than
$2500 \mathrm{~g}$ at birth, especially those born preterm (fig 1)..$^{13}$

Stillbirths have declined by only $15 \%$ since 1995. An estimated 2.6 million stillbirths occurred globally in 2009, of which $40 \%$ were intrapartum and probably due to inadequate care. ${ }^{3} 14$ In addition to prolonged and obstructed labour, untreated infections such as syphilis are an important cause of stillbirths in low resource settings. ${ }^{14}$

Optimal quality of care around childbirth and in the neonatal period could avert 113000 maternal deaths, 531000 stillbirths, and 1.3 million newborn deaths by 2020.15 Furthermore, satisfying the unmet need for family planning could prevent $29 \%$ of maternal deaths a year. ${ }^{16}$ Effective care that prevents mortality will also prevent maternal and neonatal morbidities and improve child neurodevelopmental outcomes and long term adult wellbeing. ${ }^{131718}$ The health and survival of babies and their mothers are inextricably linked, calling for coordinated care before and during pregnancy, in childbirth, and in the postnatal period.

\section{Strategic priorities}

Evidence based strategy must inform planning for maternal and newborn health and survival, with due consideration of health system dynamics and social and environmental risk factors in different countries. ${ }^{19}$ Financial security and health equity are essential. The sustainable development goals provide a framework for universal health coverage described by three, interlinked objectives-enhancing the quality and availability of essential health services; achieving equitable and optimal uptake of services in relation to need; and improving cost efficiencies and financial protection. ${ }^{20}$ The Global Financing Facility can help to drive financial innovations to achieve the sustainable development goals across the

\section{BOX 1 GLOBAL TARGETS FOR ENDING PREVENTABLE MATERNAL AND NEWBORN MORTALITY}

- Every country should reduce its maternal mortality ratio by at least two thirds from the 2010 baseline, and no country should have a rate higher than 140 deaths per 100000 live births (twice the global target)

- Every country should have a national neonatal mortality rate of $\leq 12$ per 1000 live births and a stillbirth rate of $\leq 12$ per 1000 total births

- The global maternal mortality ratio should be $<70$ maternal deaths per 100000 live births

- The global neonatal mortality rate milestone will be 9 per 1000 live births and stillbirth rate 9 per 1000 total births 


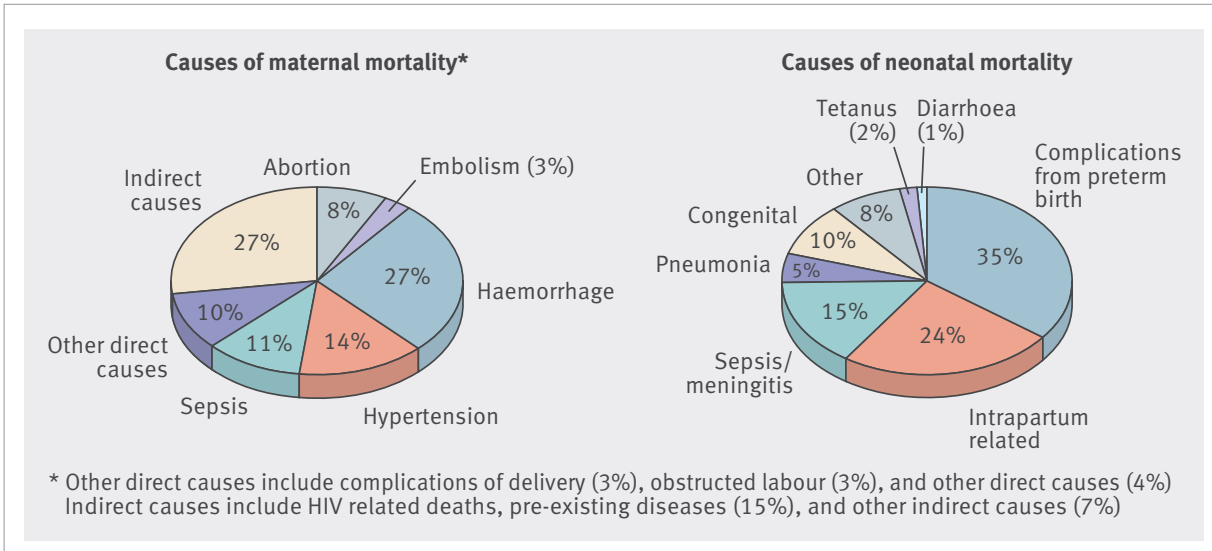

Figure 1 | Causes of maternal and neonatal mortality ${ }^{112}$

continuum of reproductive, maternal, newborn, child, and adolescent health by $2030 .^{21}$

We present five priorities, synthesised from the strategic objectives described by ENAP and EPMM (box 2).

\section{Objective 1-Strengthen care around time of birth}

Mothers and their babies are at highest risk of death during labour, childbirth, and the first week after birth. Investing in improved access to and quality of care around this time, and achieving high levels of coverage of effective interventions, has the potential to avert three million deaths of women, newborns, and stillborn babies a year, almost two million of which can be prevented around the time of birth (fig 2 ). ${ }^{15}$

Despite a global increase in coverage of skilled birth attendance, associated declines in maternal mortality have been modest, and for stillbirths virtually non-existent. ${ }^{3422} 23$ This lack of improvement highlights the need to focus on quality of care, including provider competencies and environments that enable provision of essential clinical interventions with dignity. High quality healthcare is safe, effective, timely, efficient, equitable, people centred, and respectful. ${ }^{24-26}$ Given the inextricable link between mother and baby, care should also be administered without separation of mother and baby. ${ }^{23-25}$

Effective healthcare for all major causes of death will contribute to ending preventable maternal and newborn mortality and reaching the highest attainable level of health. ${ }^{11527}$
For example, family planning will prevent closely spaced or ill timed pregnancies, which are directly correlated with increased mortality, and implementation of WHO's technical and policy guidelines for access to safe abortion will also avert deaths. ${ }^{28}$ For newborn health, improved care around the time of childbirth and special care for small and sick newborns is essential to reduce mortality. $^{8}$

\section{Objective 2-Strengthen health systems}

Health system strengthening must tackle both the hardware (essential health infrastructure, amenities, and commodities) and software (leadership and governance, transparent health information, innovation and private-public partnerships, mechanisms for participation and community engagement, and respectful care norms and values) of health systems. ${ }^{29}$ In addition, effective referral systems are needed to ensure seamless coordination across time, disciplines, and facilities.

Lack of an adequate health workforce and access to lifesaving commodities are major constraints in many countries. Thirty eight high burden countries face critical imbalances and shortages in the availability of healthcare providers. ${ }^{30}$ Nearly $90 \%$ of essential care services for maternal and neonatal health can be provided by health workers with midwifery skills, provided they are educated to achieve international standards of competency and regulated to ensure their skills are maintained. ${ }^{30}$ Yet midwives make up only $36 \%$ of the global maternity care

\section{BOX 2 PRIORITY STRATEGIC OBJECTIVES}

- Strengthen and invest in care around the time of birth, with a focus on improving quality and experience of care, while ensuring full integration of services for mothers and babies across the continuum of care

- Strengthen health systems to optimise the organisation and delivery of care, the workforce, commodities, and innovation

- Reach every woman and newborn by minimising inequities in access to and coverage of care

- Harness the power of parents, families, and communities, and engage with society

- Improve data for decision making and accountability

workforce. The lack of complete registration of births and deaths and accurate information on causes of death to inform healthcare decision making and programme evaluation limit the equitable delivery of essential, quality interventions to populations in need. Research and development is needed to tackle intransigent problems in the delivery of healthcare services and to develop technologies that make birth safer, such as simplified resuscitation or better drug delivery. The global community must also explicitly describe what constitutes quality of care and skilled attendance at birth to enable appropriate monitoring and evaluation, and WHO is developing standards that respond to the quality framework published in its vision statement (WHO, unpublished data). ${ }^{31}$

\section{Objective 3-Reach every woman and newborn}

Equity is a fundamental human right and a prerequisite to achieving the sustainable development goals. Programme planners need to better understand barriers to access and the personal factors that make care acceptable to all. Equity includes not just access to services but provision of high quality care without discrimination and meeting sustained demand at scale.

Gender equality and the empowerment of women and girls are central to a rights based approach. Gender based violence is widespread and its adverse effects include unwanted pregnancies, pregnancy complications including low birth weight and miscarriage, maternal injury and death, and sexually transmitted infections such as HIV/ AIDS. ${ }^{32}$ Strategies for empowering women in their reproductive and maternal healthcare must ensure not only the power of decision making-including whether, when, and how often to get pregnant-but the availability of options they need to exercise their choices.

The cost of health services can be a major barrier to care. Up to $11 \%$ of the population in some countries incur high out-of-pocket costs

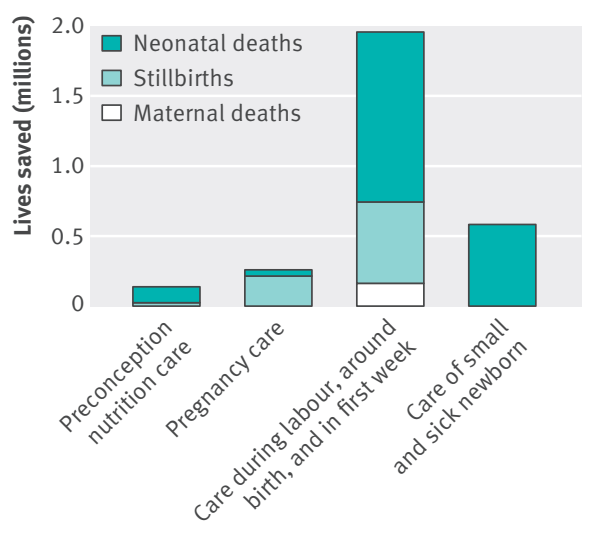

Figure 2 | Potential impact of intervention packages $^{15}$ 
for healthcare, with as many as 5\% forced into poverty by health related expenditures, including costs associated with essential maternal and newborn care. ${ }^{33}$ Universal health coverage means reaching all people in the population with essential services and protecting them from financial hardship owing to the cost of these services. Performance based financial incentives and conditional cash transfers have been effective in increasing care seeking and improving quality of care. ${ }^{34}$ Political and financial decision makers in countries and global donors must prioritise adequate and sustainable resources for maternal and newborn health.

\section{Objective 4-Harness the power of parents, families, and communities}

Ideally, families protect and care for women and newborns. Men have an important role in safeguarding family health, and they should receive support to do so. ${ }^{35}$ Evidence shows that women's groups led by a skilled facilitator can improve maternal and neonatal health through participatory learning, particularly in rural settings with low access to health services. ${ }^{36}$ Trained community health workers can assist families to strengthen preventive and caregiving practices and facilitate appropriate care seeking. Participatory mechanisms at every level of the health system can help foster community engagement and ensure that services are transparent, inclusive, and responsive to those they serve. Civil society organisations, including parent groups, can contribute substantially to social mobilisation and can hold governments and health services to account for maternal and neonatal health commitments.

\section{Objective 5-Improve data for decision making and accountability}

Changing population demographics and disease burden affect the epidemiology of risk in countries and influence the choice of strategies to prevent maternal and newborn deaths and stillbirths. ${ }^{23} 37$ Better data are needed for such planning. Establishing national registration and vital statistics systems in every country is essential for counting births and deaths and tracking progress. ${ }^{38}$ In 2012 only a third of countries had high quality civil registration systems for maternal or neonatal deaths or stillbirths; about 137 million births globally, and nearly all neonatal deaths and stillbirths, were unregistered. ${ }^{13}$ The countries where little or no empirical data are available tend to be those where the estimated burden is highest. Accurate documentation of cause of death using standard definitions is also critical to designing effective health programmes to tackle preventable causes of mortality. Countries must invest in strengthening maternal and perinatal death review and response mechanisms. ${ }^{39} 40$

Additional global indicators are needed. Innovations in information technology (including m-health) can strengthen health systems through effective, real time data collection. ${ }^{41}$ Closing the loop of monitoring and evaluation through actual use of data to understand the effects of interventions is critical in ensuring accountability. ${ }^{42}$

\section{Priority interventions}

To achieve the targets of ENAP and EPMM an essential package of effective interventions must be implemented to reach every woman, pregnancy, and newborn. But the choice of interventions and measures of success must be tailored to each country based on local context. The interventions related to maternal and newborn care that are included in the UN Global Strategy for Women's, Children's and Adolescents' Health (see data supplement on bmj.com) $)^{43}$ are not exhaustive but are prioritised based on their substantial effects on the main causes of maternal and newborn mortality and morbidity and stillbirth. ${ }^{15} 19$

\section{Conclusion}

As the agenda of the sustainable development goals emerges, healthy societies where women, adolescent girls, newborns, and children thrive, and pregnancy and childbirth are safe everywhere, should be at the heart of its ambition. Ending preventable maternal and newborn deaths and stillbirths is possible within a generation and requires focused attention on high impact interventions and strategies to improve access and quality of care. Effective care around the time of childbirth is most critical for survival and health, but comprehensive strategies and high impact interventions should span the continuum of care including before pregnancy. The detailed strategic guidance, specific targets, interventions, and milestones from the ENAP and EPMM global action plans provide guidance for countries to use in their formulation of national health plans and funding priorities.

Contributors and sources: DC, BD, RJ, MK, and LS wrote this paper on behalf of the ENAP and EPMM writing groups. We gratefully acknowledge contributions from (in alphabetical order): EPMM: Carla Abou Zahr, Agbessi Amouzou, Isabel Danel, Luc de Bernis, Mengistu Hailemariam Damtew, Lynn Freedman, Metin Gülmezoglu, Rima Jolivet, Marge Koblinsky, Gita Maya Koemarasakti, R Rajat Khosla, Matthews Mathai, Affette McCaw-Binns, Joao Paolo Souza, Annie Portela, Jeffrey Smith, Mary Ellen Stanton, Petra Ten Hoope-Bender, Joshua Vogel, and Mary Nell Wegner. ENAP: Kim Dickson, Joy Lawn, Elizabeth Mason, Lori McDougall, Juana Willumsen, Severin von Xylander. All authors contributed to drafting and reviewing the manuscript. DC, BD, LS are employees of the World Health Organization.

Competing interests: We have read and understood BMJ policy on declaration of interests and have no relevant interests to declare.
The authors alone are responsible for the views expressed in this article, which does not necessarily represent the views, decisions, or policies of WHO or the institutions with which the authors are affiliated. Provenance and peer view: Not commissioned; externally peer reviewed.

Doris Chou, medical officer ${ }^{1}$

Bernadette Daelmans, coordinator ${ }^{2}$

R Rima Jolivet,maternal health technical director ${ }^{3}$ Mary Kinney, senior specialist, global evidence and advocacy $^{4}$

Lale Say, coordinator

1 Department of Reproductive Health and Research, World Health Organization, 1211 Geneva 27, Switzerland ${ }^{2}$ Department of Maternal, Newborn, Child and Adolescent Health, World Health Organization, Geneva ${ }^{3}$ Maternal Health Task Force, Harvard TH Chan School of Public Health, Boston, MA, USA

4Save the Children, Washington, DC, USA

On behalf of the Every Newborn Action Plan (ENAP) and Ending Preventable Maternal Mortality (EPMM) working groups.

Correspondence to: D Chou choud@who.int

Additional material is published online only. To view please visit the journal online (http://dx.doi. org/10.1136/bmj.h4255)

(c) World Health Organization 2015. Licensee BMJ

This is an open access article distributed under the terms of the Creative Commons Attribution-

Noncommercial IGO License (https://creativecommons. org/licenses/by-nc/3.0/igo/), which permits use, distribution, and reproduction for non-commercial purposes in any medium, provided the original work is properly cited. In any reproduction of this article there should not be any suggestion that WHO or this article endorse any specific organisation or products. The use of the WHO logo is not permitted. This notice should be preserved along with the article's original URL.

WHO, Unicef, UNFPA, The World Bank, United Nations Population Division. Trends in maternal mortality: 1990-2013. May 2014. www.who.int/ reproductivehealth/publications/monitoring/ maternal-mortality-2013/en/.

UN Inter-agency Group for Child Mortality Estimation. Levels and trends in child mortality 2014. 2014. www. who.int/maternal_child_adolescent/documents/ levels_trends_child_mortality_2014/en/.

Cousens S, Blencowe H, Stanton C, et al. National, regional, and worldwide estimates of stillbirth rates in 2009 with trends since 1995: a systematic analysis. Lancet 2011;377:1319-30.

4 WHO. World Health Statistics 2014. www.who.int/gho/ publications/world_health_statistics/2014/en/. Kuruvilla S, Schweitzer J, Bishai D, et al. Success factors for reducing maternal and child mortality. Bull World Health Organ 2014;92:533-44B.

6 Unicef, WHO. Every newborn: an action plan to end preventable deaths. 2014. www.who.int/maternal_child adolescent/topics/newborn/enap consultation/en/. WHO. Strategies toward ending preventable maternal mortality (EPMM). 2015. http://who.int/reproductivehealth/ topics/maternal_perinatal/epmm/en/.

8 The Lancet. Every Newborn. May 2014. www.thelancet. com/series/everynewborn.

The Lancet. Stillbirth. Apr 2011. www.thelancet.com/ series/stillbirth.

10 WHO. Newborn health action plan. Resolution WHA67.10. 2014. http://apps.who.int/gb/ebwha/ pdf_files/WHA67-REC1/A67_2014_REC1-en.pdf.

11 Say L, Chou D, Gemmill A, et al. Global causes of maternal death: a WHO systematic analysis. Lancet Glob Health 2014;2:e323-33.

12 Liu L, Oza S, Hogan D, et al. Global, regional, and national causes of child mortality in 2000-13, with projections to inform post-2015 priorities: an updated systematic analysis. Lancet 2015;385:430-40.

13 Lawn JE, Blencowe H, Oza S, et al. Every Newborn: progress, priorities, and potential beyond survival. Lancet 2014;384:189-205.

14 Lawn JE, Blencowe H, Pattinson R, et al. Stillbirths: Where? When? Why? How to make the data count? Lancet 2011;377:1448-63. 
15 Bhutta ZA, Das JK, Bahl R, et al. Can available interventions end preventable deaths in mothers, newborn babies, and stillbirths, and at what cost? Lancet 2014:384:347-70.

16 Ahmed S, Li Q, Liu L, Tsui AO. Maternal deaths averted by contraceptive use: an analysis of 172 countries. Lancet 2012:380:111-25.

17 Reichenheim ME, Zylbersztajn F, Moraes $\mathrm{CL}$ Lobato G. Severe acute obstetric morbidity (near-miss): a review of the relative use of its diagnostic indicators. Arch Gynecol Obstet 2009; 280:337-43.

18 Harrison MS, Ali S, Pasha O, et al. A prospective population-based study of maternal, fetal, and neonatal outcomes in the setting of prolonged labor, obstructed labor and failure to progress in low- and middle-income countries. Reprod Health 2015. 12(Suppl 2): S9.

19 WHO, Aga Khan University, PMNCH. Essential interventions, commodities and guidelines for reproductive, maternal, newborn and child health. 2011. www.who.int/pmnch/ knowledge/publications/201112_essential_ interventions/en/.

20 WHO. Health systems financing: the path to universa coverage. World health report 2010. www.who.int/ whr/2010/en/.

21 World Bank. Global financing facility in support of every woman every child. Jul 2015. www.worldbank.org/en/ topic/health/brief/global-financing-facility-in-supportof-every-woman-every-child.

22 IEG World Bank, IFC, MIGA. Delivering the millennium development goals to reduce maternal and child mortality. A systematic review of impact evaluation evidence. 2013. www.oecd.org/derec/norway/ WORLDBANKDeliveringtheMDGtoreducematernaland childmortality.pdf.

23 Souza JP, Gülmezoglu AM, Vogel J, et al. Moving beyond essential interventions for reduction of maternal mortality (the WHO Multicountry Survey on Maternal and Newborn Health): a cross-sectional study. Lancet 381:1747-55
24 Renfrew MJ, McFadden A, Bastos MH, et al. Midwifery and quality care: findings from a new evidenceinformed framework for maternal and newborn care. Lancet 2014:384:1129-45.

25 Institute of Medicine. Crossing the Quality Chasm: A New Health System for the 21st Century. 2001. http:// iom.nationalacademies.org/Reports/2001/ Crossing-the-Quality-Chasm-A-New-Health-System-forthe-21st-Century.aspx.

26 WHO. The prevention and elimination of disrespect and abuse during facility-based childbirth. 2014. http:// apps.who.int/iris/bitstream/10665/134588/1/ WHO_RHR_14.23_eng.pdf?ua=1\&ua=1.

27 Kassebaum NJ, Bertozzi-Villa A, Coggeshall MS, et al. Global, regional, and national levels and causes of maternal mortality during 1990-2013: a systematic analysis for the Global Burden of Disease Study 2013. Lancet 2014;384:980-1004.

28 WHO. Safe abortion: technical and policy guidance fo health systems. Second edition. 2012. www.who.int/ reproductivehealth/publications/unsafe abortion/9789241548434/en/.

29 Sheikh K, Gilson L, Agyepong IA, Hanson K, Ssengooba F, Bennett S. Building the field of health policy and systems research: framing the questions. PLoS Med 2011;8:e1001073.

30 UNFPA. The state of the world's midwifery 2014. http:// unfpa.org/public/home/pid/16021.

31 Tunçalp Ö, Were WM, MacLennan C, et al. Quality of care for pregnant women and newborns-the WHO vision. BJOG 2015:122:1045-9.

32 UNFPA, UNIFEM, OSAGI. Combating gender-based violence: a key to achieving the MDGs. 2005. www. unfpa.org/publications/combating-gender-based-violencekey-achieving-mdgs.

33 WHO. Health systems financing: the path to universal coverage. World health report 2010. www.who.int/ whr/2010/en/.

34 Meessen B, Soucat A, Sekabaraga C. Performancebased financing: just a donor fad or a catalyst towards comprehensive health-care reform? Bull World Health Organ 2011;89:153-6
35 World Health Organization. WHO recommendations on health promotion interventions for maternal and newborn care. 2015. www.who.int/maternal child adolescent/ documents/health-promotion-interventions/en/.

36 WHO. WHO recommendation on community mobilization through facilitated participatory learning and action cycles with women's groups for maternal and newborn health. 2014. www.who.int/maternal child_adolescent/documents/communitymobilization-maternal-newborn/en/.

37 Oza S, Lawn JE, Hogan DR, Mathers C, Cousens $\mathrm{SN}$. Neonatal cause-of-death estimates for the early and late neonatal periods for 194 countries: 2000-2013. Bull World Health Organ 2015;93:19-28.

38 Commission on Information and Accountability for Women's and Children's Health. Keeping promises, measuring results. 2011. www.who.int/topics/ millennium_development_goals/accountability commission/Commission_Report_advance_copy.pdf.

39 WHO. The WHO application of ICD-10 to deaths during pregnancy, childbirth and puerperium: ICD MM. 2012. www.who.int/reproductivehealth/publications/ monitoring/9789241548458/en/.

40 WHO. Maternal death surveillance and response: technical guidance. Information for action to prevent maternal death. 2013. www.who.int/maternal child adolescent/ documents/maternal_death_surveillance/en/.

41 Mehl G, Labrique A. Prioritizing integrated mHealth strategies for universal health coverage Science 2014;345:1284-7.

42 Agarwal S, Heltberg R, Diachok M. Scaling up social accountability in World Bank operations. 2009. www. gsdrc.org/go/display\&type=Document\&id=4062.

43 Every Woman Every Child. Shaping the future for healthy women, children, and adolescents: learn more about the process to update the global strategy. 2015. www.everywomaneverychild.org/global-strategy-2.

Cite this as: $B M J$ 2015;351:h4255

Priority interventions for maternal and newborn care 